\title{
BMJ Global Health Association between education and major adverse cardiac events among patients with acute coronary syndrome in the Arabian Gulf
}

\author{
Ibrahim Al-Zakwani, ${ }^{1}$ Ruth M Mabry, ${ }^{2}$ Mohammad Zubaid, ${ }^{3}$ Alawi A Alsheikh-Ali, ${ }^{4}$ \\ Wael Almahmeed, ${ }^{5}$ Abdullah Shehab, ${ }^{6}$ Wafa Rashed ${ }^{7}$
}

To cite: Al-Zakwani I,

M Mabry R, Zubaid M, et al. Association between education and major adverse cardiac events among patients with acute coronary syndrome in the Arabian Gulf. BMJ Glob Health 2019:4:e001278. doi:10.1136/ bmjgh-2018-001278

Handling editor Seye Abimbola

Received 3 November 2018 Revised 24 November 2018 Accepted 3 December 2018

Check for updates

C Author(s) (or their employer(s)) 2019. Re-use permitted under CC BY-NC. No commercial re-use. See rights and permissions. Published by BMJ.

For numbered affiliations see end of article.

Correspondence to Dr Ibrahim Al-Zakwani; ial_zakwani@yahoo.com

\section{ABSTRACT}

Introduction The objective of this study was to evaluate the association between education and major adverse cardiac events in patients with acute coronary syndrome (ACS) in the Arabian Gulf.

Methods Data were analysed from 3874 consecutive patients diagnosed with ACS admitted to 29 hospitals in four Arabian Gulf countries from January 2012 to January 2013. Education was defined as any type of formal training from primary school and above. MACE included stroke/ transient ischaemic attack (TIA), myocardial infarction (MI), all-cause mortality and readmissions for cardiac reasons. Results The overall mean age was $60 \pm 13$ years and $67 \%(n=2579)$ were men. A total of $53 \%(n=2039)$ of the patients had some form of school education. Adjusting for demographic and clinical characteristics as well as socioeconomic measures (insurance type and employment), at 12-month follow-up, educated patients were significantly less likely to have had MACE (adjusted OR (aOR): $0.55 ; 95 \% \mathrm{Cl} 0.44$ to $0.68 ; \mathrm{p}<0.001$ ) than those with no formal education. The lower rate of events was also consistent across all MACE components: stroke/TIA (aOR: 0.56; 95\% Cl 0.33 to 0.94; $p=0.030$ ), Ml (aOR: 0.58; $95 \% \mathrm{Cl} 0.38$ to $0.86 ; \mathrm{p}=0.008$ ), all-cause mortality (aOR: $0.58 ; 95 \% \mathrm{Cl} 0.39$ to $0.87 ; p=0.009$ ) and readmissions for cardiac reasons (aOR: $0.61 ; 95 \% \mathrm{Cl} 0.48$ to 0.77 ; $\mathrm{p}<0.001)$. MACE outcomes were consistent across men and women and across countries.

Conclusions Education was associated with lower MACE events in patients with ACS in the Arabian Gulf. Interventions promoting healthy lifestyles and management of clinical risk factors for patients with low health literacy are urgently required.

\section{INTRODUCTION}

Cardiovascular diseases (CVDs) are one of the leading causes of death and disability in the Arabian Gulf and worldwide despite remarkable advances in their management. ${ }^{1-4}$ An inverse association between measures of socioeconomic status, like educational attainment, and CVDs has been known for decades. ${ }^{5}$ Education has been associated

\section{Key questions}

What is already known?

- Most of the patients with acute coronary syndrome (ACS) in the West are literate.

- Education has been inversely associated with major adverse cardiac events (MACEs) in patients with ACS in the West.

What are the new findings?

- Compared with their illiterate counterparts, literate Arabian Gulf patients with ACS were associated with fewer MACEs, namely: stroke/transient ischaemic attack, myocardial infarction, mortality and readmissions for cardiac reasons.

- All patients in the Arabian Gulf received free universal health insurance including free medications.

What do the new findings imply?

- Interventions promoting healthy lifestyles and management of clinical riskfactors for patients with low health literacy are urgently required.

with significantly lower cardiovascular events (ie, cardiovascular mortality, coronary heart disease (CHD), myocardial infarction (MI) and stroke) in various regions of the world including USA, Europe, Australia, New Zealand, China and Asia Pacific. ${ }^{5-10}$ Although, most of these studies were done in the West, it is likely that the positive association of education is universal. Also, it is possible that economic inequality within a country may magnify the disparity in cardiovascular outcomes between the least and highest educated groups. ${ }^{11}$

However, similar studies on the association of education with major adverse cardiac events (MACEs) in the Arabian Gulf are scarce. The effect of potentially modifiable risk factors associated with myocardial infarction (INTERHEART) study evaluated the effect of education on the risk of developing 
first non-fatal MI, while Doulah et al only looked at the association between education and severity of coronary artery disease (CAD) in patients undergoing coronary angiography. ${ }^{12}{ }^{13}$ Furthermore, access to healthcare, a concern raised in studies regarding socioeconomic associations with CVD, ${ }^{7911}$ is unlikely to have limited effect given the high universal health coverage in the Arabian Gulf. ${ }^{14}$ Hence, the aim of this study was to evaluate the potential association of education with MACE in patients with acute coronary syndrome (ACS) in the Arabian Gulf, using the Gulf COAST dataset, a prospective, multicentre, multinational registry of consecutive Gulf citizens hospitalised with ACS in four Arabian Gulf countries. ${ }^{15}$

\section{METHODS}

The methods of the Gulf COAST registry have been previously reported. ${ }^{15}$ In summary, the Gulf COAST registry was a prospective, multicentre, multinational, longitudinal, cohort study of consecutive citizens with a diagnosis of ACS, from four Arabian Gulf countries (Bahrain, Kuwait, Oman and United Arab Emirates) and admitted to 29 hospitals between January 2012 and January 2013. The registry enrolled patients $\geq 18$ years of age and diagnosed according to the American College of Cardiology clinical data standards. ${ }^{16}$ Only those that were able to provide informed consent were included into the study.

Education was defined as any formal education from primary school and above. MACE included stroke/transient ischaemic attack (TIA), MI, all-cause mortality and readmissions for cardiac reasons.

Data collected included patient demographics (age, gender, employment status, marital status, health insurance, body mass index and tobacco and alcohol use), medical history and risk factors related to MACE, prior medication use, laboratory data, clinical presentation and management during hospital stay including medications, reperfusion therapy and procedures and discharge medications. Follow-up was performed at 1 month, 6 months and 12 months from the date of enrolment and was carried out by clinic visits or telephone interviews.

\section{Statistical analysis}

For categorical variables, frequencies and percentages were reported. Differences between educated and non-educated groups were analysed using Pearson's $\chi^{2}$ tests (or Fisher's exact tests for cells $<5$ ). Mean and SD were used to summarise the data for continuous variables and analyses performed using Student's t-test. The relationships between education (yes/no) and MACE (stroke/TIA, MI, all-cause mortality, readmissions for cardiac reasons and overall MACE) were evaluated using multiple logistic regression using the simultaneous method and adjusting for Global Registry of Acute Coronary Events (GRACE) risk score for in-hospital mortality, which has been validated in an Arabian Gulf ACS Registry. ${ }^{17}$ Apart from from GRACE risk score, the logistic models were also adjusted for gender, employment status, marital status, insurance type, demographic and clinical characteristics. Interaction terms between education and employment status as well as between education and gender were also tested.

The goodness-of-fit of the multivariable logistic models was examined using the Hosmer-Lemeshow goodness-of-fit statistic ${ }^{18}$ as well as the $C$-index. ${ }^{19}$ An a priori two-tailed level of significance was set at the 0.05 level. Statistical analyses were conducted using STATA V.13.1.

\section{RESULTS}

The Gulf COAST registry enrolled 4044 patients. The present analysis included only patients who were discharged alive from the index admission $(n=3784)$. The overall mean age of the cohort was $60 \pm 13$ years, of which $67 \%(\mathrm{n}=2579)$ were males. A total of $29 \%$ of the patients were employed $(n=1117)$ and $85 \%(n=3281)$ were married. Forty per cent of the patients $(n=1537)$ were current or prior smokers, and $3.1 \% \quad(\mathrm{n}=121)$ of the patients were alcohol consumers. Comorbid conditions were common in this cohort particularly hypertension $(n=2510 ; 65 \%)$, dyslipidaemia $(n=2189 ; 57 \%)$ and diabetes mellitus $(n=2071 ; 53 \%)$.

A total of $53 \%(n=2039)$ of the patients had any formal education (24\% had below secondary school (high school), 16\% had completed secondary school (high school), $4.2 \%$ had some sort of vocational training, $6.4 \%$ graduated from college while $1.7 \%$ had postgraduate training). Those with formal education (compared with those that were illiterate) were younger (54 years vs 66 years; $\mathrm{p}<0.001$ ) and more likely to be male ( 82 vs $49 \%$; $\mathrm{p}<0.001$ ), employed ( $49 \%$ vs $6.2 \%$; $\mathrm{p}<0.001$ ), married (91\% vs $77 \%$; $\mathrm{p}<0.001)$, current or prior smoker $(54 \%$ vs $23 \% ; \mathrm{p}<0.001)$ and alcohol consumers $(4.6 \%$ vs $1.5 \%$; $\mathrm{p}<0.001)$ but less likely to have a prior MI (24\% vs $29 \%$; $\mathrm{p}=0.001)$, hypertension ( $57 \%$ vs $73 \%$; $\mathrm{p}<0.001)$, diabetes mellitus $(50 \%$ vs $57 \% ; \mathrm{p}<0.001)$ and prior stroke/TIA $(4.7 \%$ vs $9.3 \% ; \mathrm{p}<0.001)$ than those without formal education. Educated patients were also more likely to present with a lower heart rate ( 84 vs 86 beats/min; $\mathrm{p}<0.001$ ), systolic blood pressure (141 vs $144 \mathrm{~mm} \mathrm{Hg}$; $\mathrm{p}<0.001$ ), serum creatinine ( 81 vs $84 \mu \mathrm{mol} / \mathrm{L} ; \mathrm{p}<0.001$ ) and GRACE risk score (114 vs 139; $\mathrm{p}<0.001)$, and had higher left ventricular ejection fraction $(50 \%$ vs $48 \%$; $\mathrm{p}<0.001)$. They were also less likely to present with a high Killip class $(\mathrm{p}<0.001)$ (table 1$)$.

Table 2 shows medication utilisation prior to admission and postdischarge stratified by education status. While $98 \%(\mathrm{n}=3623)$ of the cohort was treated optimally with the dual antiplatelet combination (aspirin and clopidogrel concurrently), only $52 \% \quad(n=1922)$ of the patients were prescribed the five-drug regimen (aspirin, clopidogrel, ACE inhibitor/angiotensin receptor blocker (ARB), statin and beta blocker) concurrently, which was significantly higher among educated participants in contrast to their illiterate counterparts ( $59 \%$ vs $45 \%$; $\mathrm{p}<0.001)$.

The overall MACE rate was $32.9 \%(n=1276)$ with significant differences among the groups as shown in 
Table 1 Demographic and clinical characteristics of patients with acute coronary syndrome in the Arabian Gulf stratified by education status: findings from Gulf Coast registry

\begin{tabular}{|c|c|c|c|c|}
\hline \multirow[b]{2}{*}{$\begin{array}{l}\text { Characteristic, } \mathbf{n}(\%) \text { unless } \\
\text { specified otherwise }\end{array}$} & \multirow[b]{2}{*}{$\begin{array}{l}\text { All } \\
(\mathrm{N}=3874)\end{array}$} & \multicolumn{2}{|l|}{ Educated } & \multirow[b]{2}{*}{$P$ value } \\
\hline & & $\begin{array}{l}\text { No } \\
(n=1835)\end{array}$ & $\begin{array}{l}\text { Yes } \\
(n=2039)\end{array}$ & \\
\hline \multicolumn{5}{|l|}{ Demographic } \\
\hline Age, mean $\pm S D$, years & $60 \pm 13$ & $66 \pm 10$ & $54 \pm 12$ & $<0.001$ \\
\hline Male gender & $2579(67)$ & $898(49)$ & $1681(82)$ & $<0.001$ \\
\hline Employed & $1117(29)$ & $114(6.2)$ & $1003(49)$ & $<0.001$ \\
\hline Married & 3281 (85) & $1418(77)$ & $1863(91)$ & $<0.001$ \\
\hline $\mathrm{BMI}$, mean $\pm \mathrm{SD}, \mathrm{kg} / \mathrm{m}^{2}$ & $29.1 \pm 9.0$ & $28.7 \pm 9.6$ & $29.5 \pm 8.4$ & 0.005 \\
\hline Smoking (current or prior) & $1537(40)$ & $430(23)$ & $1107(54)$ & $<0.001$ \\
\hline Alcohol & $121(3.1)$ & $28(1.5)$ & $93(4.6)$ & $<0.001$ \\
\hline \multicolumn{5}{|l|}{ Medical history } \\
\hline Prior MI & 1007 (26) & $523(29)$ & $484(24)$ & 0.001 \\
\hline Dyslipidaemia & $2189(57)$ & $1057(58)$ & $1132(56)$ & 0.191 \\
\hline Premature CAD & $597(15)$ & $147(8.0)$ & $450(22)$ & $<0.001$ \\
\hline Hypertension & $2510(65)$ & $1344(73)$ & $1166(57)$ & $<0.001$ \\
\hline Diabetes mellitus & $2071(53)$ & $1051(57)$ & $1020(50)$ & $<0.001$ \\
\hline Stroke/TIA & $266(6.9)$ & $171(9.3)$ & $95(4.7)$ & $<0.001$ \\
\hline \multicolumn{5}{|c|}{ Clinical (parameters) at presentation } \\
\hline $\mathrm{HR}$, mean $\pm \mathrm{SD}, \mathrm{bpm}$ & $85 \pm 21$ & $86 \pm 21$ & $84 \pm 20$ & $<0.001$ \\
\hline $\mathrm{SBP}$, mean $\pm \mathrm{SD}, \mathrm{mm} \mathrm{Hg}$ & $142 \pm 27$ & $144 \pm 27$ & $141 \pm 27$ & $<0.001$ \\
\hline $\mathrm{DBP}, \mathrm{mean} \pm \mathrm{SD}, \mathrm{mm} \mathrm{Hg}$ & $81 \pm 16$ & $80 \pm 16$ & $82 \pm 16$ & $<0.001$ \\
\hline Crea, p50 (IQR), $\mu \mathrm{mol} / \mathrm{L}$ & $82(66-104)$ & $84(66-114)$ & $81(68-98)$ & $<0.001$ \\
\hline LVEF, mean $\pm S D, \%$ & $49 \pm 13$ & $48 \pm 13$ & $50 \pm 13$ & $<0.001$ \\
\hline GRACE risk, mean \pm SD & $126 \pm 40$ & $139 \pm 39$ & $114 \pm 37$ & $<0.001$ \\
\hline Killip class & & & & $<0.001$ \\
\hline I: no heart failure & $3099(80)$ & $1340(73)$ & $1759(86)$ & \\
\hline II: rales & $493(13)$ & $307(17)$ & $186(9.1)$ & \\
\hline III: pulmonary oedema & $260(6.7)$ & $174(9.5)$ & $86(4.2)$ & \\
\hline IV: cardiogenic shock & $22(0.6)$ & $14(0.8)$ & $8(0.4)$ & \\
\hline Discharged diagnosis & & & & $<0.001$ \\
\hline LBBB MI & $30(0.8)$ & $20(1.1)$ & $10(0.5)$ & \\
\hline NSTEMI & $1820(47)$ & $1022(56)$ & $798(39)$ & \\
\hline STEMI & $928(24)$ & $341(19)$ & $587(29)$ & \\
\hline Unstable angina & $1094(28)$ & $452(25)$ & $642(32)$ & \\
\hline
\end{tabular}

BMI was missing in 35 subjects, HR in 2 subjects, SBP in 3 subjects, DBP in 3 subjects, creatinine in 19 subjects, LVEF was missing in 1335 subjects, GRACE in 21 subjects and 2 subjects in discharged diagnosis.

Percentages might not add up to $100 \%$ due to rounding off.

BMI, body mass index; CAD, coronary artery disease; Crea, first serum creatinine; DBP, diastolic blood pressure; HR, heart rate; LBBB, left bundle branch block; LVEF, left ventricular ejection fraction; LBBB MI, myocardial infarction; NSTEMI, non-ST myocardial infarction; SBP, systolic blood pressure; STEMI, ST myocardial infarction; TIA, transient ischaemic attack; bpm, beats per minute; p50, median.

table 3. Adjusting for demographic and clinical characteristics as well as socioeconomic measures (insurance type, employment and marital status), at 12-month follow-up, educated patients with ACS were significantly less likely to have had MACE (adjusted OR (aOR): $0.55 ; 95 \%$ CI 0.44 to $0.68 ; \mathrm{p}<0.001)$. The lower rate of events was also consistent across all MACE components:
stroke/TIA (aOR: $0.56 ; 95 \%$ CI 0.33 to $0.94 ; \mathrm{p}=0.030$ ), MI (aOR: $0.58 ; 95 \%$ CI 0.38 to $0.86 ; \mathrm{p}=0.008$ ), all-cause mortality (aOR: $0.58 ; 95 \%$ CI 0.39 to $0.87 ; \mathrm{p}=0.009$ ) and readmissions for cardiac reasons (aOR: $0.61 ; 95 \% \mathrm{CI}$ 0.48 to $0.77 ; \mathrm{p}<0.001)$. The interaction terms between education and employment status as well as between education and gender were not significant in all the 
Table 2 Medication utilisation of the patients with acute coronary syndrome in the Arabian Gulf stratified by education status: findings from Gulf Coast registry

\begin{tabular}{|c|c|c|c|c|}
\hline \multirow{2}{*}{$\begin{array}{l}\text { Characteristic, } \mathbf{n}(\%) \text { unless } \\
\text { specified otherwise }\end{array}$} & \multirow{2}{*}{$\begin{array}{l}\text { All } \\
(\mathrm{N}=3874)\end{array}$} & \multicolumn{2}{|l|}{ Educated } & \multirow[b]{2}{*}{$P$ value } \\
\hline & & No $(n=1835)$ & Yes $(n=2039)$ & \\
\hline \multicolumn{5}{|l|}{ Prior medications ( $\mathrm{N}=2878$ ) } \\
\hline Aspirin & $2288(80)$ & $1247(83)$ & $1041(76)$ & $<0.001$ \\
\hline Clopidogrel & $834(29)$ & $451(30)$ & $383(28)$ & 0.212 \\
\hline ACEls & $1490(52)$ & $833(55)$ & $657(48)$ & $<0.001$ \\
\hline ARBs & 557 (19) & 267 (18) & $290(21)$ & 0.023 \\
\hline Beta blockers & $1755(61)$ & $935(62)$ & $820(60)$ & 0.172 \\
\hline Statins & $2319(81)$ & $1240(82)$ & $1079(79)$ & 0.008 \\
\hline Other LLDs & $60(2.1)$ & $14(0.9)$ & $46(3.4)$ & $<0.001$ \\
\hline Oral nitrates & $995(35)$ & $633(42)$ & $362(26)$ & $<0.001$ \\
\hline CCBs & $578(20)$ & $300(20)$ & $278(20)$ & 0.848 \\
\hline \multicolumn{5}{|c|}{ Discharged medications $(\mathrm{N}=3681) \dagger$} \\
\hline Aspirin & $3559(97)$ & $1682(96)$ & $1877(97)$ & 0.028 \\
\hline Clopidogrel & $2698(73)$ & $1146(65)$ & $1552(80)$ & $<0.001$ \\
\hline ACEls & $2475(67)$ & 1189 (68\%) & $1286(67)$ & 0.439 \\
\hline ARBs & $558(15)$ & $269(15)$ & $289(15)$ & 0.758 \\
\hline Beta blockers & $3123(85)$ & $1426(81)$ & $1697(88)$ & $<0.001$ \\
\hline Statins & $3568(97)$ & $1699(97)$ & $1869(97)$ & 0.951 \\
\hline Other LLDs & $87(2.4)$ & $32(1.8)$ & $55(2.9)$ & 0.041 \\
\hline Oral nitrates & $2212(60)$ & $1197(68)$ & $1015(53)$ & $<0.001$ \\
\hline CCBs & $570(15)$ & $289(17)$ & $281(15)$ & 0.108 \\
\hline Dual antiplatelets & $3623(98)$ & $1726(99)$ & $1897(98)$ & 0.670 \\
\hline Five-drug regimen & 1922 (52) & $784(45)$ & 1138 (59) & $<0.001$ \\
\hline
\end{tabular}

Percentages might not add up to $100 \%$ due to rounding off.

Dualantiplatelets, aspirin and clopidogrel concurrently; five drug regimen, concurrentprescribing of aspirin, clopidogrel, ACEI/ARB, statin, beta blocker.

*In the prior history, 996 patients had missing medications, while during thospital discharge, 193 patients had missing medications.

ACEI, angiotensin-converting enzyme inhibitor; ARB, angiotensin II receptor blocker; CCB, calcium channel blocker; LLD, lipid lowering drug.

various outcome models $(\mathrm{p}>0.05$ in all the logistic regressions).

\section{DISCUSSION}

The present analysis of a large, prospective, multicentre, multinational study from the Arabian Gulf demonstrated that education was associated with significantly lower risk of MACE at 1-year follow-up among patients with ACS. The apparent protective effect of education was consistent across several outcomes including stroke/ TIA, recurrent MI, all-cause mortality and readmissions for cardiac reasons. The findings are even more unique given the fact that all patients had free universal access to healthcare unlike in the prior studies, which had varying degrees of access to care.

The association of education with CVD, stroke, MI and CVD risk factors is well known. ${ }^{5-10}$ Evidence demonstrates that less educated patients have increased comorbidities, ${ }^{20}$ as seen in our study. Furthermore, less educated patients are more likely to experience worse clinical presentation, less likely to receive secondary prevention therapies and attend cardiac rehabilitation. ${ }^{79}$ Despite patients presenting with a clinical history that portend a poor prognosis, a large Global Utilization of Streptokinase and tPA for Occluded Coronary Arteries III (GUSTO-III) study found that education was independently inversely correlated with 1-year mortality confirming findings from smaller studies. ${ }^{9}$ Our study is the first to demonstrate this association in the Arabian Gulf.

Individuals with less education also tend to have increased number of behavioural risk factors like smoking, unhealthy diet and physical inactivity. The Monitoring Project on Risk Factors and Chronic Diseases in the Netherlands (MORGEN) study found that behavioural and biological factors like smoking, obesity, physical inactivity and hypertension explained more than half of the increased risk of CHD among people with low education. ${ }^{21}$ Controlling for these risks factors has been found to attenuate but not eliminate the association of education on health and thus calls for further examination of these associations. ${ }^{11}$ Addressing 
Table 3 Association between education (Edu) and major adverse cardiac events (MACEs) in patients with acute coronary syndrome in the Arabian Gulf: findings from Gulf Coast registry

\begin{tabular}{|c|c|c|c|c|c|c|c|c|}
\hline \multirow[b]{2}{*}{ Outcome } & \multicolumn{4}{|c|}{ Univariate statistics } & \multicolumn{4}{|c|}{ Multivariate logistic regression } \\
\hline & $\begin{array}{l}\text { All } \\
(\mathrm{N}=3874), \mathrm{n} \\
(\%)\end{array}$ & $\begin{array}{l}\text { No Edu } \\
(n=1835), n \\
(\%)\end{array}$ & $\begin{array}{l}\text { Edu }(n=2039), \\
n(\%)\end{array}$ & P value & $\begin{array}{l}\text { Adjusted OR (95\% } \\
\text { Cl) }\end{array}$ & $\begin{array}{l}\text { Adjusted } \\
\text { P value }\end{array}$ & HL & ROC \\
\hline \multicolumn{9}{|l|}{ Stroke/TIA } \\
\hline 12 months & $143(3.7)$ & $105(5.7)$ & $38(1.9)$ & $<0.001$ & 0.56 (0.33 to 0.94$)$ & 0.030 & 0.333 & 0.72 \\
\hline \multicolumn{9}{|c|}{ Myocardial infarction } \\
\hline \multicolumn{9}{|c|}{ All-cause mortality } \\
\hline 12 months & 317 (8.2) & $236(12.9)$ & $81(4.0)$ & $<0.001$ & 0.58 (0.39 to 0.87$)$ & 0.009 & 0.791 & 0.79 \\
\hline \multicolumn{9}{|c|}{ Readmissions for cardiac reasons } \\
\hline 12 months & $990(25.6)$ & $572(31.2)$ & $418(20.5)$ & $<0.001$ & 0.61 (0.48 to 0.77$)$ & $<0.001$ & 0.613 & 0.64 \\
\hline
\end{tabular}

MACE included stroke/TIA, myocardial infarction, mortality and readmissions for cardiac reasons. For 6-month and 12-month follow-up, the events were cumulative.

Multivariate analyses were conducted using logistic regression models using the simultaneous method. The covariates in the models included GRACE risk score (derived from age, heart rate, systolic blood pressure, serum creatinine, cardiac arrest at admission, ST segment deviation on electrocardiogram (EKG), abnormal cardiac enzymes and Killip class) as well as gender, smoking status, marital status, employment status, body mass index, diabetes mellitus, peripheral artery disease, left ventricular ejection fraction, acute coronary syndrome type and use of evidence-based cardiac medications at hospital discharge (aspirin, clopidogrel, beta blocker, statin, ACE inhibitor (ACEI) or angiotensin receptor blocker (ARB)).

Over the 1-year follow-up period, a total of 20 patients (0.5\%) were lost to follow-up.

HL, Hosmer-Lemeshow p value; ROC, area under the receiver operating curve (also known as c-statistic); TIA, transient ischaemic attack.

these risks remains critical for primary and secondary prevention.

Our findings indicate that a significantly higher proportion of educated patients were prescribed the recommended five-drug regimen compared with their uneducated counterparts. Although all patients were provided free healthcare including medications in the Arabian Gulf, this inequity in prescribing practice is concerning and may explain, in part, the poorer outcomes for less educated groups. Studies have shown that people with lower socioeconomic levels receive inferior treatment. ${ }^{20}$ For example, a retrospective study in Taiwan found that low-income coronary artery bypass surgery was associated with poorer quality of services. ${ }^{22}$ Further research is needed to better understand the observed inequality in prescribing practices in the Arabian Gulf.

Finally, health literacy, which is strongly correlated with education, may explain the education-associated differences in the observed cardiovascular outcomes. ${ }^{20}$ Poor health literacy is associated with increased risk behaviours (ie, physical inactivity and unhealthy diet), ${ }^{23}$ decreased medications adherence ${ }^{24}$ and health interventions ${ }^{25} 26$ and poor outcomes. ${ }^{20}$ In their study on health literacy in Danish individuals with CVD, Aaby et $a t^{23}$ found significant positive associations between health literacy and physical activity, healthier diet and higher self-reported health status. A prospective study of patients with heart failure in the USA reported that low health literacy was associated with increased risk of hospitalisation and mortality. ${ }^{26} \mathrm{~A}$ nurse-coordinated intervention carried out in the Netherlands for patients with $\mathrm{CAD}$ appears to be effective among patients with poor health literacy. It involved four patient visits with a trained nurse focusing on promoting healthy lifestyles, managing biometric risk factors and increasing medication adherence and resulted in similar reductions in CVD risk profiles regardless of level of health literacy. ${ }^{27}$ This promising initiative could be adapted and tested for patients with CVD in the Arabian Gulf; this is particularly important since nearly half of the patients are illiterate.

Our study has limitations. First, due to the inherent nature of uncontrolled observational study design, its ability to assess causal relationships is limited. Second, the analysis relies only on patients admitted to the hospital with a diagnosis of ACS and hence cannot be generalised to the entire population of patients with ACS that do not end up being hospitalised. Third, the study also only analysed those patients with ACS who survived following an ACS event. Fourth, the utilisation of the five-drug regimen did not take into account the contraindications and/or side effects of any of the components of this combination. Fifth, we reported all-cause 12 month mortality where, if data were available, cardiovascular mortality would have been more pertinent.

\section{CONCLUSIONS}

To our knowledge, this is the first study from the Arabian Gulf region to demonstrate that any formal patient education was less likely to be associated with 12 months 
cumulative stroke/TIA, MI, all-cause mortality, readmissions for cardiac reasons and overall MACE in ACS patients compared with no education. Since a high proportion of patients with ACS have limited, if any education, interventions that promote healthy lifestyles and management of risk factors for this group are urgently required.

\section{Author affiliations}

'Department of Pharmacology \& Clinical Pharmacy, College of Medicine \& Health Sciences, Sultan Qaboos University, Muscat, Oman

${ }^{2}$ Office of the Regional Director, WHO Regional Office for the Eastern Mediterranean Region, Cairo, Egypt

${ }^{3}$ Department of Medicine, Faculty of Medicine, Kuwait University, Kuwait, Kuwait ${ }^{4}$ College of Medicine, Mohammed Bin Rashid University of Medicine and Health Sciences, Dubai, UAE

${ }^{5}$ Heart and Vascular Institute, Cleveland Clinic Abu Dhabi, Abu Dhabi, UAE ${ }^{6}$ Internal Medicine Department, College of Medicine and Health Sciences (CMHS), UAE University, Al Ain, UAE

${ }^{7}$ Department of Medicine, Mubarak Al-Kabeer Hospital, Ministry of Health, Safat, Kuwait

Contributors IA contributed towards literature search, data analysis and interpretation, figures and tables and writing of the manuscript. RM contributed towards literature search, interpretation and writing of the manuscript. MZ and WR contributed towards data management and oversight of the Gulf COAST registry. MZ, AAA-A, WA, AS and WR contributed towards drafting of the protocol, study design of the Gulf COAST registry, data collection and critical evaluation and interpretation of the results and the manuscript.

Funding Gulf COAST is an investigator-initiated study that was supported by Astra Zeneca with oversight by Kuwait University (project code XX02/11).

Disclaimer Neither Kuwait University nor AstraZeneca had any role in the study design, data collection, data analysis or writing the manuscript. The views expressed in this manuscript are those of the authors and do not necessarily reflect those of their affiliated institutions.

Competing interests MZ and WA received speakers' bureau from Sanofi, Boehringer Ingleheim, Amgen and Astra Zeneca. AAA-A has received honoraria related to consulting and speaker's activities from Boehringer-Ingelheim, Bayer and Pfizer.

\section{Patient consent Obtained.}

Ethics approval The study was approved by the local institutional ethics committees of participating centres in the various Arabian Gulf countries.

Provenance and peer review Not commissioned; externally peer reviewed.

Data sharing statement № additional data are available.

Open access This is an open access article distributed in accordance with the Creative Commons Attribution Non Commercial (CC BY-NC 4.0) license, which permits others to distribute, remix, adapt, build upon this work non-commercially, and license their derivative works on different terms, provided the original work is properly cited, appropriate credit is given, any changes made indicated, and the use is non-commercial. See: http://creativecommons.org/licenses/by-nc/4.0

\section{REFERENCES}

1. Vos T, Barber RM, Bell B, et al. Global, regional, and national incidence, prevalence, and years lived with disability for 301 acute and chronic diseases and injuries in 188 countries, 1990-2013: a systematic analysis for the Global Burden of Disease Study 2013. The Lancet 2015;386:743-800.

2. Anderson JL, Adams CD, Antman EM, et al. ACC/AHA 2007 guidelines for the management of patients with unstable angina/ non-ST-Elevation myocardial infarction: a report of the American College of Cardiology/American Heart Association Task Force on Practice Guidelines (Writing Committee to Revise the 2002 Guidelines for the Management of Patients With Unstable Angina/Non-ST-Elevation Myocardial Infarction) developed in collaboration with the American College of Emergency Physicians, the Society for Cardiovascular Angiography and Interventions, and the Society of Thoracic Surgeons endorsed by the American
Association of Cardiovascular and Pulmonary Rehabilitation and the Society for Academic Emergency Medicine. J Am Coll Cardiol 2007;50:e1-157.

3. Wright RS, Anderson JL, Adams CD, et al. 2011 ACCF/AHA focused update incorporated into the ACC/AHA 2007 Guidelines for the Management of Patients with Unstable Angina/Non-ST-Elevation Myocardial Infarction: a report of the American College of Cardiology Foundation/American Heart Association Task Force on Practice Guidelines developed in collaboration with the American Academy of Family Physicians, Society for Cardiovascular Angiography and Interventions, and the Society of Thoracic Surgeons. J Am Coll Cardiol 2011;57:e215-e367.

4. IbanezB, JamesS, AgewallS. 2017 ESC Guidelines for the management of acute myocardial infarction in patients presenting with ST-segment elevation: The Task Force for the management of acute myocardial infarction in patients presenting with ST-segment elevation of the European Society of Cardiology (ESC). Eur Heart J 2017:39:119-77.

5. Liu K, Cedres LB, Stamler J, et al. Relationship of education to major risk factors and death from coronary heart disease, cardiovascular diseases and all causes, Findings of three Chicago epidemiologic studies. Circulation 1982;66:1308-14.

6. Woodward M, Peters SAE, Batty GD, et al. Socioeconomic status in relation to cardiovascular disease and cause-specific mortality: a comparison of Asian and Australasian populations in a pooled analysis. BMJ Open 2015;5:e006408.

7. Gerber Y, Weston SA, Killian JM, et al. Neighborhood income and individual education: effect on survival after myocardial infarction. Mayo Clin Proc 2008;83:663-9.

8. Kelly MJ, Weitzen S. The association of lifetime education with the prevalence of myocardial infarction: an analysis of the 2006 Behavioral Risk Factor Surveillance System. J Community Health 2010;35:76-80.

9. Mehta RH, O'Shea JC, Stebbins AL, et al. Association of mortality with years of education in patients with ST-segment elevation myocardial infarction treated with fibrinolysis. J Am Coll Cardio 2011;57:138-46.

10. Hu B, Li W, Wang X, et al. Marital status, education, and risk of acute myocardial infarction in Mainland China: the INTER-HEART study. $J$ Epidemiol 2012;22:123-9.

11. Vathesatogkit $P$, Batty GD, Woodward $M$. Socioeconomic disadvantage and disease-specific mortality in Asia: systematic review with meta-analysis of population-based cohort studies. $J$ Epidemiol Community Health 2014;68:375-83.

12. Rosengren A, Subramanian SV, Islam S, et al. Education and risk for acute myocardial infarction in 52 high, middle and low-income countries: INTERHEART case-control study. Heart 2009;95:2014-22.

13. Daoulah A, Elkhateeb OE, Nasseri SA, et al. Socioeconomic factors and severity of coronary artery disease in patients undergoing coronary angiography: a multicentre study of Arabian Gulf states. Open Cardiovasc Med J 2017;11:47-57.

14. World Health Organization, 2018. The global health observatory. universal health coverage. Available from: http://apps.who.int/gho/ portal/uhc-overview.jsp [Accessed 21 Jun 2018]

15. Zubaid M, Thani KB, Rashed W, et al. Design and rationale of gulf locals with acute coronary syndrome events (gulf coast) registry. Open Cardiovasc Med J 2014;8:88-93.

16. Weintraub WS, Karlsberg RP, Tcheng JE, et al. ACCF/AHA 2011 key data elements and definitions of a base cardiovascular vocabulary for electronic health records: a report of the american college of cardiology foundation/american heart association task force on clinical data standards. J Am Coll Cardiol 2011:58:202-22.

17. Panduranga $\mathrm{P}$, Sulaiman $\mathrm{K}, \mathrm{Al}-$ Zakwani I, et al. Utilization and determinants of in-hospital cardiac catheterization in patients with acute coronary syndrome from the Middle East. Angiology 2010;61:744-50.

18. Lemeshow S, Hosmer DW. A review of goodness of fit statistics for use in the development of logistic regression models. Am J Epidemiol 1982;115:92-106.

19. Hanley JA, McNeil BJ. The meaning and use of the area under a receiver operating characteristic ( $\mathrm{ROC})$ curve. Radiology 1982;143:29-36.

20. Schultz WM, Kelli HM, Lisko JC, et al. Socioeconomic status and cardiovascular outcomes: Challenges and interventions. Circulation 2018:137:2166-78.

21. Kershaw KN, Droomers M, Robinson WR, et al. Quantifying the contributions of behavioral and biological risk factors to socioeconomic disparities in coronary heart disease incidence: the MORGEN study. Eur J Epidemiol 2013;28:807-14.

22. Yu TH, Hou YC, Chung KP. Do low-income coronary artery bypass surgery patients have equal opportunity to access excellent quality 
of care and enjoy good outcome in Taiwan? Int J Equity Health 2014;13:64.

23. Aaby A, Friis K, Christensen B, et al. Health literacy is associated with health behaviour and self-reported health: a large populationbased study in individuals with cardiovascular disease. Eur J Prev Cardiol 2017;24:1880-8.

24. Miller TA. Health literacy and adherence to medical treatment in chronic and acute illness: a meta-analysis. Patient Educ Couns 2016:99:1079-86.
25. Mattson CC, Rawson K, Hughes JW, et al. Health literacy predicts cardiac knowledge gains in cardiac rehabilitation participants. Health Educ J 2015;74:96-102.

26. Fabbri M, Yost K, Finney Rutten LJ, et al. Health literacy and outcomes in patients with heart failure: a prospective community study. Mayo Clin Proc 2018;93:9-15.

27. van Schaik TM, Jørstad HT, Twickler TB, et al. Cardiovascular disease risk and secondary prevention of cardiovascular disease among patients with low health literacy. Neth Heart J 2017;25(78):446-54. 